\title{
ASSESSING THE COSTAL RISKS IN DOHA \\ MUNICIPALITY SPATIAL DEVELOPMENT PLANS \\ THROUGH STRATEGIC ENVIRONMENTAL \\ ASSESSMENT (SEA)
}

Elmalky, M. G. ${ }^{(1)}$; Al-Ansi, M. A. ${ }^{(2)}$ and Al-Marri, A. M. S. ${ }^{(3)}$

1) Department of Environmental Basic Sciences, Institute of environmental studies \& research, Ain Shams University 2) Department of Biological \& Environmental Sciences, College of Arts and Sciences, Qatar University 3) Laboratories section, Quality and Safety Department, Public Works Authorities, State of Qatar

\begin{abstract}
Strategic Environmental Assessment (SEA) is designed to help countries to make their policies, plans and programs more sustainable. The aim of this research is to ensure that environmental considerations are fully integrated into a decision-making process at the earliest possible stages. Implementing SEA of spatial plans has the potential to reduce the negative environmental impacts and enhance the positive effects.

Coasts of Doha are projected to be exposed to increasing risks, including coastal erosion, due to climate change and sea-level rise. The level of flooding in Qatar increases with the increase in sea level rise for the two climate change scenarios 2040 and 2100 (ICZMPCCSLR, 2014). This increase is associated with the increase in the impact on both socioeconomic and natural systems. Doha municipality spatial development plans must consider the flooding and sea-level rise of Doha's coasts. Future iterations of the National Spatial Strategy and/or National Development Plan must recognize the increasing vulnerability of coastal populations to coastal and climate change risks, e.g. flooding and sea level rise and establish a strong institutional system for monitoring of coastal indicators, identifying and assessing in particular, the land subsidence in the coastal area. Strategic Environmental Assessment (SEA) for future development plans must Carrying out with strong follow up taking Sea Level Rise (SLR) into
\end{abstract}


consideration and building up a strong early warning system and contingency plans against flooding.

Key words: Doha, Qatar, sea, costal, msdp, flooding, sea level rise.

\section{INTRODUCTION}

Coastal areas are subject to intense pressures from a diverse range of sources. Coasts host many of the world's major centers of commerce and represent highly desirable locations for residential, recreational and tourism related activities (Martínez et al., 2007). The rapid development of coastal areas is leading to a parallel increase in vulnerability of coastal hazards. Coastal hazards are "a function of the presence of human beings and their myriad activities in interaction with naturally occurring coastal processes" (Domurat and Wakeman, 1991, p. 92). These natural processes are construed as 'coastal hazards' as they may result in the loss of life or property. Many such hazards, such as coastal erosion, are natural continuous environmental processes which constantly remodel and reshape coastlines. Others, such as tsunamis, are more episodic and catastrophic in nature and often have immediate and dramatic effects. Vulnerability of coastal communities to such events is likely to be exacerbated by continuing population growth (Nicholls et al., 1999) and by the impacts of climate change (Duxbury and Dickinson, 2007). Coastal population growth, urbanization and expanding coastal tourism increase pressure on coastal environments, resulting in ecosystem degradation (Cooper and McKenna, 2009; Duxbury and Dickinson, 2007). This degradation reduces the long-term resilience of coastal systems (Duxbury and Dickinson, 2007) and increases the vulnerability of local inhabitants to coastal hazards. In terms of climate change impacts, the 
Intergovernmental Panel on Climate Change states that "coasts are projected to be exposed to increasing risks, including coastal erosion, due to climate change and sea-level rise. The effect will be exacerbated by increasing human-induced pressures on coastal areas" (IPCC,2007).

Location of the studied area: The state of Qatar is a peninsula with an area of $11,437 \mathrm{Km} 2$, located halfway along the west coast of the Arabian Gulf, and projecting approximately $160 \mathrm{Km}$ into the central zone of the Gulf along its north-south axis. Qatar is surrounded by the Arabian Gulf from the north and east, and by the gulf of Bahrain from the west.

Present situation of the studied area: Qatar may lose around 3\%, 8\%, and $13 \%$ of its area if there is a sea level increase by $1 \mathrm{~m}, 3 \mathrm{~m}$, and $5 \mathrm{~m}$ respectively (AFED, 2009). The Ministry of Municipality and Urban Planning in Qatar recently conducted a study on climate change and sea level rise titled "Integrated Coastal Zone Management Plan for the State of Qatar" (ICZMCCSLR, 2014). 
J. Environ. Sci.

Institute of Environmental Studies and Research - Ain Shams University
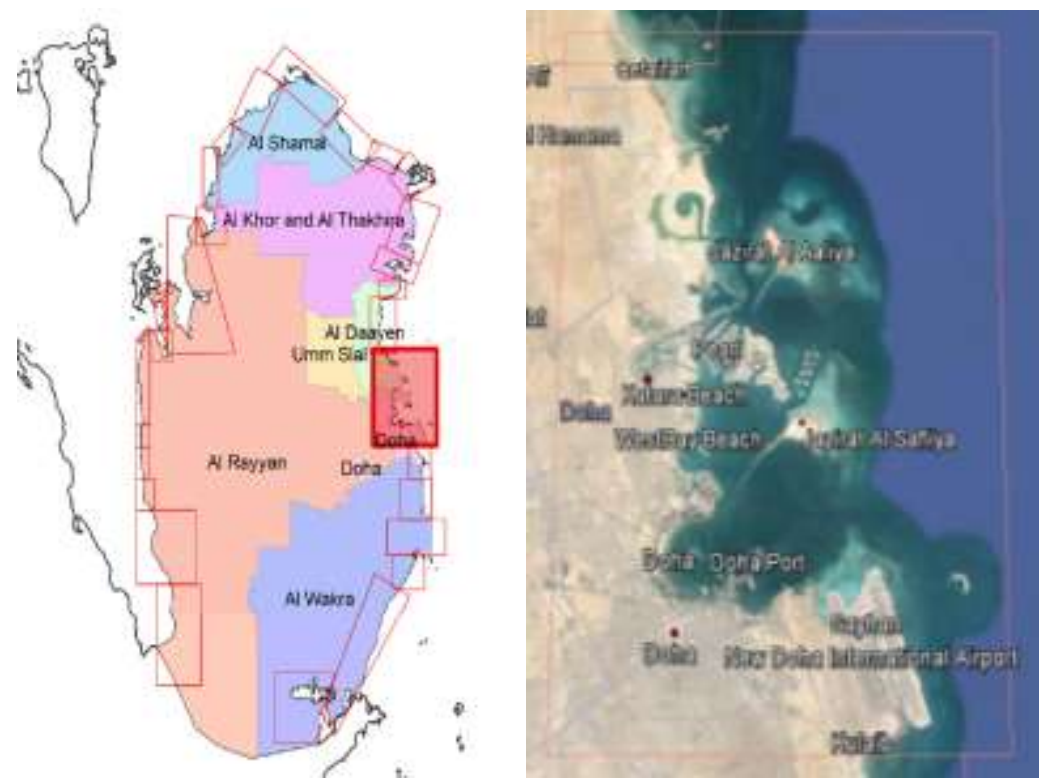

Fig(1): location Map of the studied area

The study provided information about the impact of climate change on the whole coastal zone of Qatar. Sea level rise was also examined at a number of scenarios as projected by the IPCC in their fifth assessment (IPCC, 2013). The output of the two scenarios the mean sea level rise by 2100 was estimated to be $0.52 \mathrm{~m}$ for RCP 4.5 (Representative concentration pathway of medium coastal impact), and $0.74 \mathrm{~m}$ for RCP8.5 (Representative concentration pathway of high coastal impact).

Mean Sea level rise is observed using different databases. Permanent Service for Mean Sea Level (PSMSL) is an instrumental data source; which is responsible for collection, interpretation and analysis of data. It has a global network of tide gauge. 
Measurements are available from 1982 till 2010 (ICZMP-CCSLR, 2014). One of its stations is located inside the Arabian Gulf (Bahrain), called the Mina Sulman station. Figure 2 represents the trend in mean sea level rise between 1980-2010. The unit used was in mm. A linear trend is used to fit the gap between 1998 and 2003. The trend estimated $3.28 \mathrm{~mm} /$ year $( \pm 1.1 \mathrm{~mm} /$ year) and $2.97 \mathrm{~mm} /$ year $( \pm 2.55 \mathrm{~mm} /$ year $)$ for the periods $1982-2003$ and 1993-2008 respectively. The gap in data between 1998 and 2003 increased the uncertainty of the trend estimation (ICZMP-CCSLR, 2014).

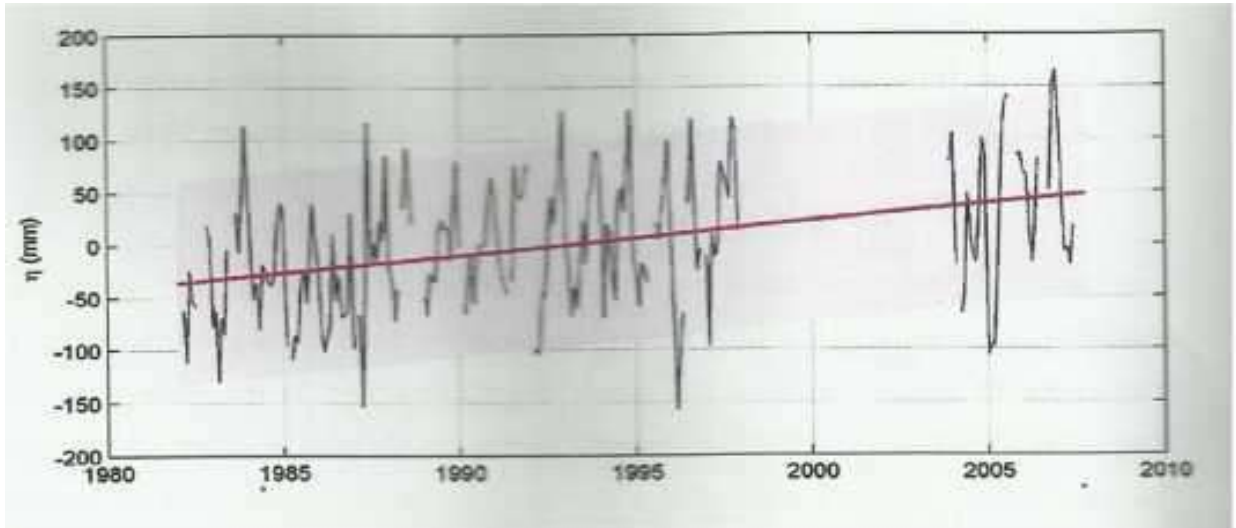

Fig(2): The trend in mean sea level rises during time series 1980-2010 of the Mina Sulman station from the PSLMSL data set. The linear fitting and the confidence intervals (95\%) (ICZM-CCSLR, 2014)

Doha station located at Doha port is another source to estimate seal level rise changes. This tidal station gives measurement from 1976 to 2013. Figure 3 represents the linear trend produce from Doha station. The linear trend initially recorded $1.47 \mathrm{~mm} /$ year between period 1976-2013, but later revised the estimate to $2.8 \mathrm{~mm} /$ year for the periods 1993-2013 (ICZMP-CCSR, 2014). 
J. Environ. Sci.

Institute of Environmental Studies and Research - Ain Shams University

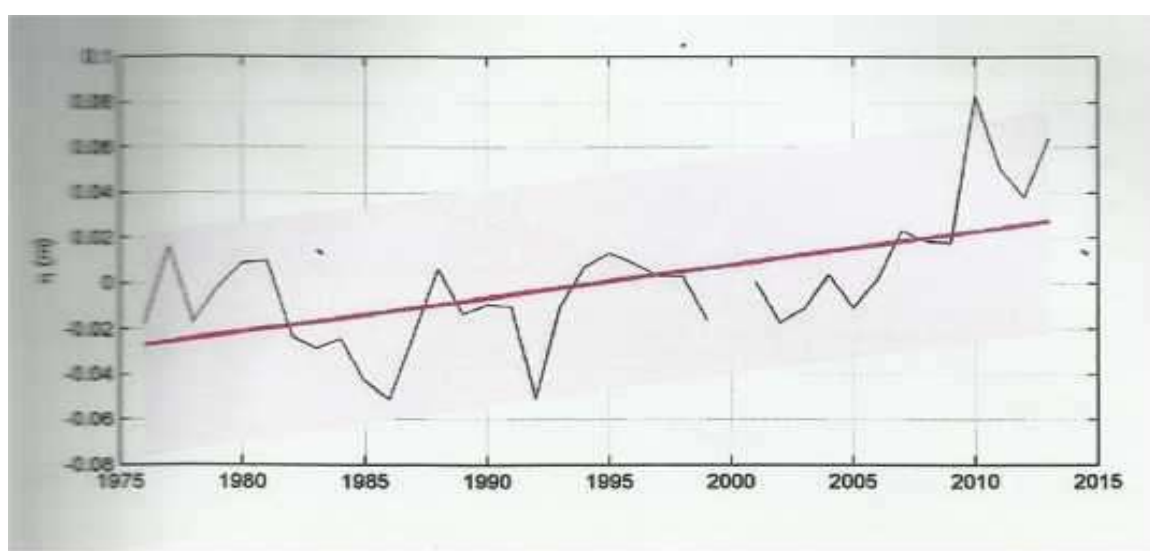

Fig(3): The linear trend in mean sea level produced by Doha station. The linear fitting and the confidence intervals (95\%) (ICZM-CCSLR, 2014)

The trend in mean sea level rise on local (Qatar) scale is summarized in Table 1. Local trend analysis is established from the climate change and sea level rise, study in Qatar (ICZM-CCSLR, 2014). Regional and global analysis are based on the intergovernmental fifth assessment report on climate change (IPCC, 2013), and other studies such as Ayhan and Alothman, 2009; Church and White, 2011; Nerem et al., 2010. The table describe the data used, the period, and any technical comment involved in trend calculation.

Table(1): Summary of Local mean sea level Trends (ICZM-CCSLR, 2014)

\begin{tabular}{|c|c|c|c|}
\hline Data set & $\begin{array}{c}\text { Trend } \\
(\mathrm{mm} / \mathrm{year})\end{array}$ & Period & $\begin{array}{l}\text { Technical } \\
\text { Comments }\end{array}$ \\
\hline $\begin{array}{l}\text { Mina Sulman } \\
\text { station (PSMSL } \\
\text { data set) }\end{array}$ & $\begin{array}{c}3.28 \pm 1.1 \\
2.97 \pm 2.55\end{array}$ & $\begin{array}{l}1983-2007 \\
1993-2007\end{array}$ & $\begin{array}{l}\text { Local estimation without Glacial } \\
\text { isostatic adjustment } \\
\text { correction } 66 \% \text { completeness }\end{array}$ \\
\hline Doha Station & $\begin{array}{l}1.47 \pm 0.69 \\
2.8 \pm 1.58\end{array}$ & $\begin{array}{l}1975-2013 \\
1993-2013\end{array}$ & $\begin{array}{l}\text { Local estimation without Glacial } \\
\text { isostatic adjustment( GIA) } \\
\text { correction annual records }\end{array}$ \\
\hline
\end{tabular}


According to the report current level of flooding in Qatar will increase with the increase in sea level rise for the two climate change scenarios 2040 and 2100 (ICZMPCCSLR, 2014). This increase is associated with the increase in the impact on both socioeconomic and natural systems.

Coastal flooding of Doha City: The coastal flooding in Doha city is modeled by 2100 under RCP 4.5 and RCP 8.5 sea level projections. The model used to simulate coastal flooding is RFSM-EDA, a 2D flood model developed in HR Wallingford with sub-element topography. The hydraulic inundation process is modeled taking into account the ground elevation and topographic features (Romanowicz and Beven, 2003; Zhang and Cundy, 1989). Therefore, the result accuracy depends mainly on the quality of the digital elevation model (DEM). The outputs of the model are water-depth and velocities at each mesh element which permits to develop damage functions to evaluate the risk. Figure 4 shows the coastal flooding in the present climate, by 2040 and by 2100 for RCP 4.5 and RCP 8.5. The level to model the coastal flooding by 2040 is based on historical extrapolation of mean sea level. The level by 2100 is $0.52 \mathrm{~m}$ for the RCP4.5 and $0.73 \mathrm{~m}$ for the RCP8.5. It can be observed the higher spatial extension of coastal flooding and the higher water-depth by 2100 and for the scenario with very high greenhouse gas emissions (RCP8.5). 
J. Environ. Sci.

Institute of Environmental Studies and Research - Ain Shams University
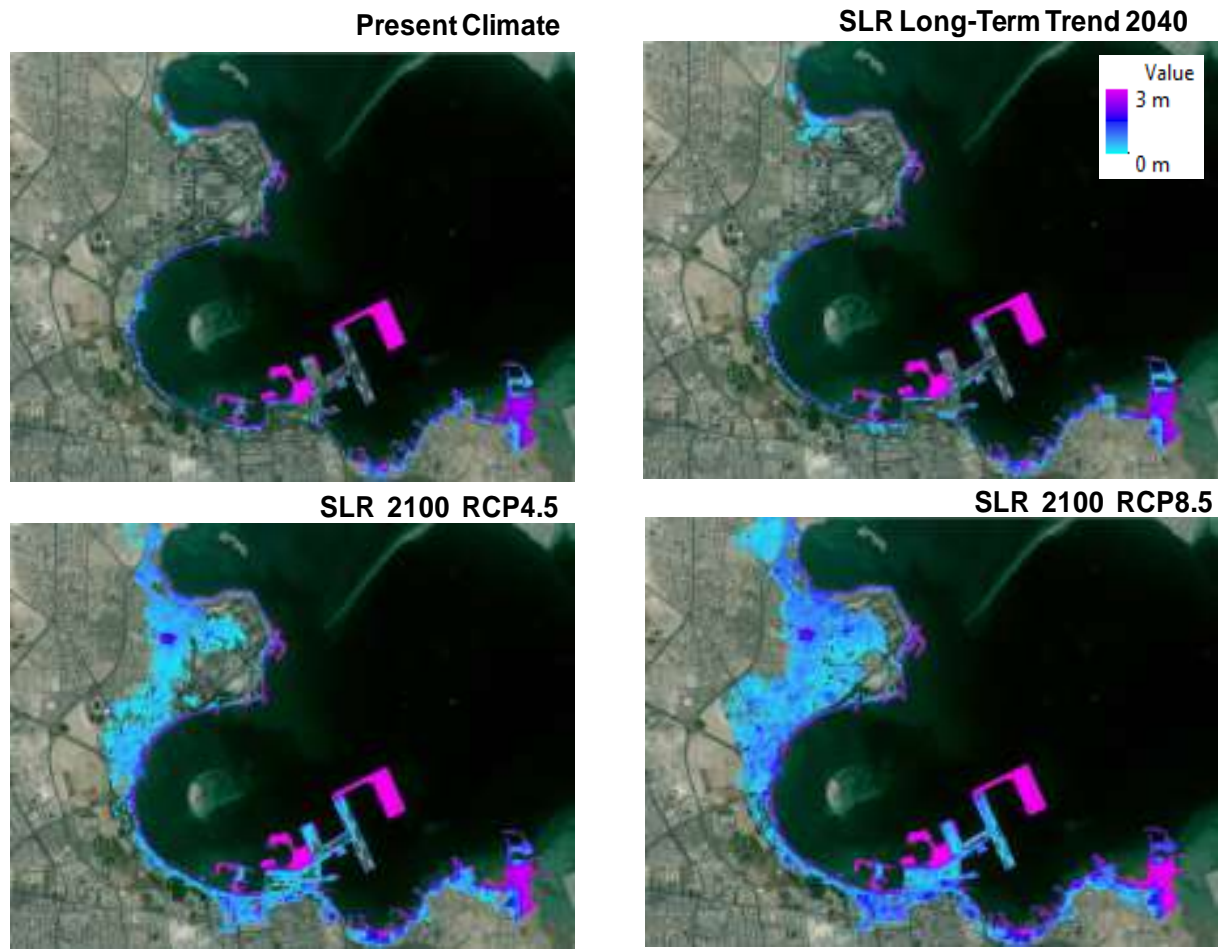

Fig(4): Coastal flooding under different scenarios: Present Climate, by 2040 based on historical mean sea level extrapolation, by 2100 under RCP 4.5 mean sea level projections, by 2100 under RCP 8.5 mean sea level projections.

Flooding impacts are evaluated by means of the flooding level, resulting from the addition of the mean sea level, astronomical tide, storm surge and run-up, generated by waves. Flooding affects cities, industrial areas and roads and airports located close to the shoreline. Figs.5,6 \& 7 show the areas of Doha, which exposed to flooding under three scenarios. The four impact levels are represented by color scale: negligible impact (green), low impact (yellow), moderate impact (orange) and high impact (red). 

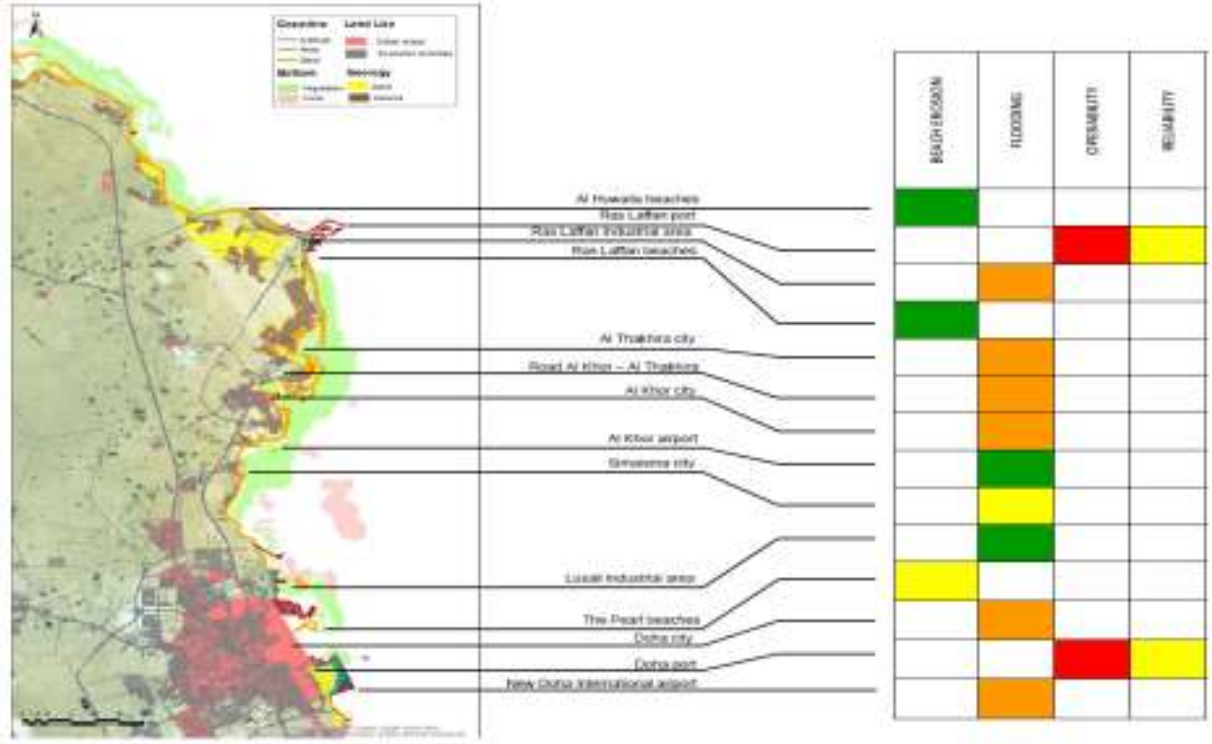

Fig.(5): Area of Doha city exposed to coastal flooding under scenario 2040 based on historical mean sea level extrapolation.
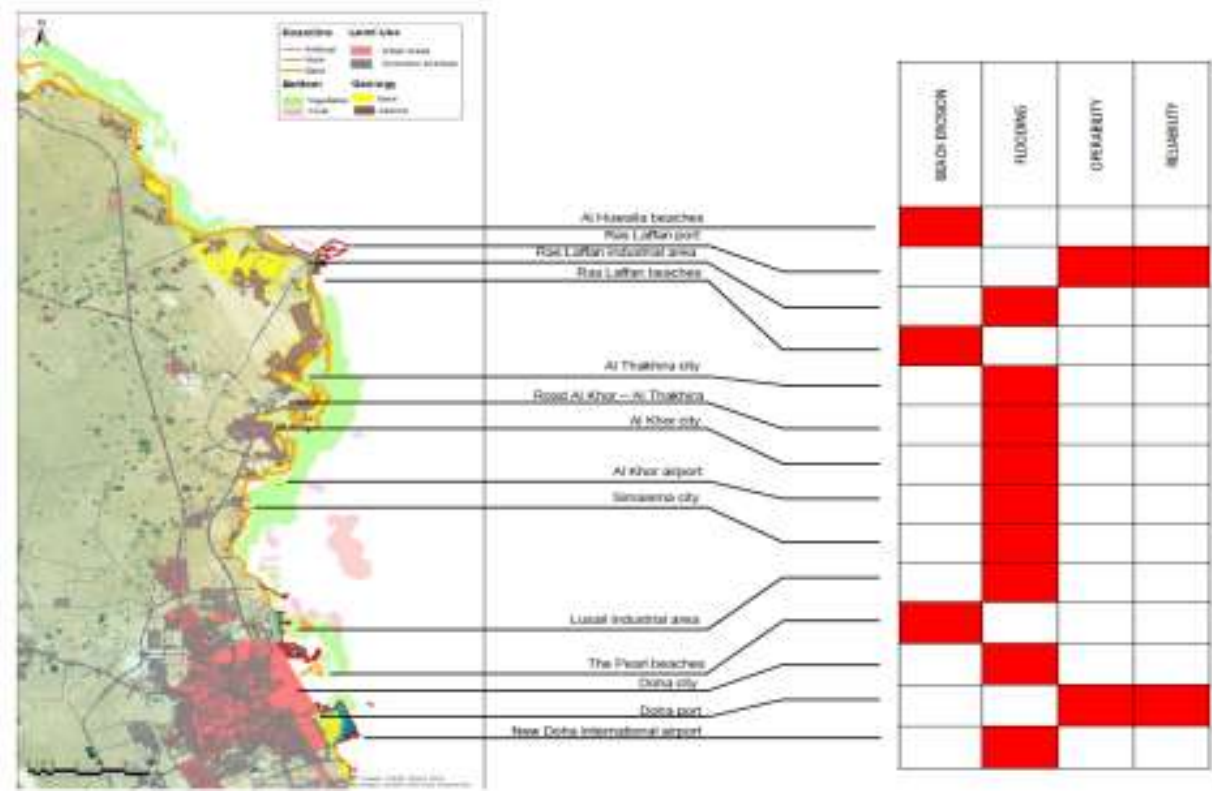

Fig(6): Area of Doha city exposed to coastal flooding under scenario by 2100 under RCP 4.5 mean sea level projections. 

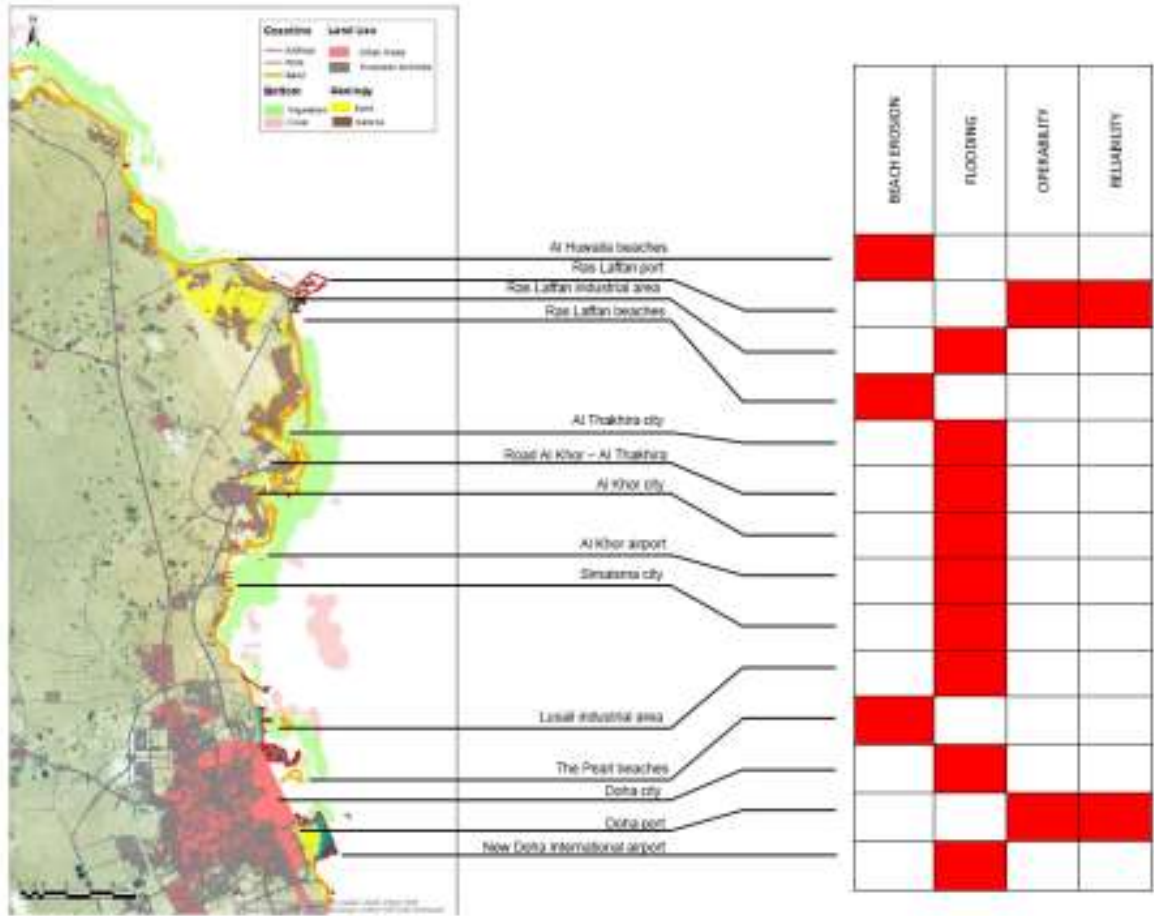

Fig.(7): Area of Doha city exposed to coastal flooding under scenario by 2100 under RCP 8.5 mean sea level projections.

Doha Municipality Spatial Development Plans (MSDPs): The Doha MSDP seeks to achieve the orderly planning and development of land and infrastructure across the Doha municipality in response to expected growth. It sets out a clearly defined urban structure and a coordinated development approach for the municipality over the next 20 years.

The Doha MSDP provides the land use planning framework and regulations for the entire Municipality and the strategic context for growth and change to 2032. Doha Municipality is divided into a series of Land Use 
Zones identifying the particular land which uses may be permitted in the zone. Development within each zone may be classified as being either:

- Permitted: Permitted Uses are developments that have negligible impacts on and/or beyond the site, and raise no policy implications. They are generally suitable and appropriate ion each site within the zone and do not require a development application or approval;

- Conditional: Conditional Uses are developments that require a Planning Application to be submitted from the applicant for the proposed Land Use. Conditional Uses can be approved, approved with conditions or declined. Conditional Uses are usually more complex or could potentially result in negative impacts on and/or beyond the site, but which can be mitigated or removed through design, environmental or usage measures; or

- Prohibited: Prohibited Uses are developments that are not appropriate or are likely to result in a too high an impact in a particular Land Use Zone or which cannot comply with one or more explicit requirements.

The translation of the National Vision and the sustainable guiding principles into a spatial and physical development dimension gave rise to a vision for the future urban development of the country which has guided the preparation of the Qatar National Development Framework (QNDF) and subsequent Municipality Spatial Development Plans (MSDPs). The QNDF vision is to:

"Create a role model for Sustainable Urban Living and Livable Towns and Cities in the 21 st Century" 
The Doha MSDP has been prepared in accordance with the QNDF as the regulatory framework for managing development in a way that advances the purpose of the QNDF, the National Development Strategy and the Qatar National Vision 2030 (QNV2030).

Doha Municipality: Doha is the capital of Qatar, its largest city with about half of the nation's population, and forms a substantial component of the greater Doha metropolitan area which itself accommodates more than $80 \%$ of Qatar's population.

It is the heart of Qatar. Its history captures Qatar's past and its more recent dramatic growth represents Qatar's future. As the capital city of Qatar much of the significant built environment assets of the country are located in Doha.

The Municipality is made up of a number of different character areas spread across three distinct geographic locations all of which fall within the greater Metropolitan Doha. The majority of the Municipality is located around the historic core of Doha with a mix of older and newer residential areas plus large scale commercial areas such as the West Bay tower district and the Grand Hamad banking area.

This Core area is the financial and commercial heart of the Qatar and the seat of Government. It also contains major hotels as well as large scale public facilities such as the Hamad Medical City, several university and higher education campuses, a number of mixed-use metro and town centers, the existing sea and air ports, and the new Hamad International Airport which provides the main gateway to Qatar. The two other major locations are the 
satellite areas of the Doha Industrial Area, and the Whole sale Market Area located within the adjoining All Rayyan municipalities.

At the municipality level Doha connects the sea to the desert. At the city level, Doha commands an enviable position in the Gulf, defined geographically by the bay, the Corniche and the Grand Park. To the north is the Katara Cultural Village, the prestigious Pearl-Doha residential development located on a reclaimed island and planned to accommodate 45,000 persons, and the tower district of the West Bay Capital City Centre. The old historic city with the Souq Waqif, Mshereib urban renewal development, the museum quarter, the Grand Park and the Emiri Diwan have a central location. The Corniche and existing sea port form the eastern border of the city which is framed to the west by lower and medium density residential communities.

Doha is experiencing a renaissance and is quickly becoming one of the major cultural capitals of the Middle East. The future of Doha as an economic driver and the major employment location in the country will be built on the developing knowledge, technology, education, science, art and culture sectors as part of a diversified economy

Population and Employment Growth Expectations - 2010 - 2032: A substantial part of Doha municipality is already developed. The population in Doha City is expected to grow from 797,000 in 2010 to $1,078,410$ in 2017 , representing an increase of 281,410 . Beyond that a decrease of 158,144 people is expected between 2017 and 2032, to result in a 2032 population of 1,920,266; as major urban development and urban renewal projects are completed and the demographic make-up of the city changes. Economic 
J. Environ. Sci.

Institute of Environmental Studies and Research - Ain Shams University

activity is expected to increase the number of jobs in the Municipality from 769,000 in 2010 to over $1,000,000$ by 2032. Many of these new jobs in a diversified economy are expected to be located within centers throughout Doha particularly those with good access to the metro public transit system presently under construction.

Table(2): Doha City and Qatar: Population (2010-2032)

\begin{tabular}{|c|c|}
\hline Years & Population \\
\hline 2010 & 797,000 \\
\hline 2017 & $1,078,410$ \\
\hline 2032 & $1,920,266$ \\
\hline
\end{tabular}

Development Strategy: The Development Strategy for Doha Municipality is summarized spatially in the Doha Municipality Structure Plan derived from the QNDF (Figure 8).

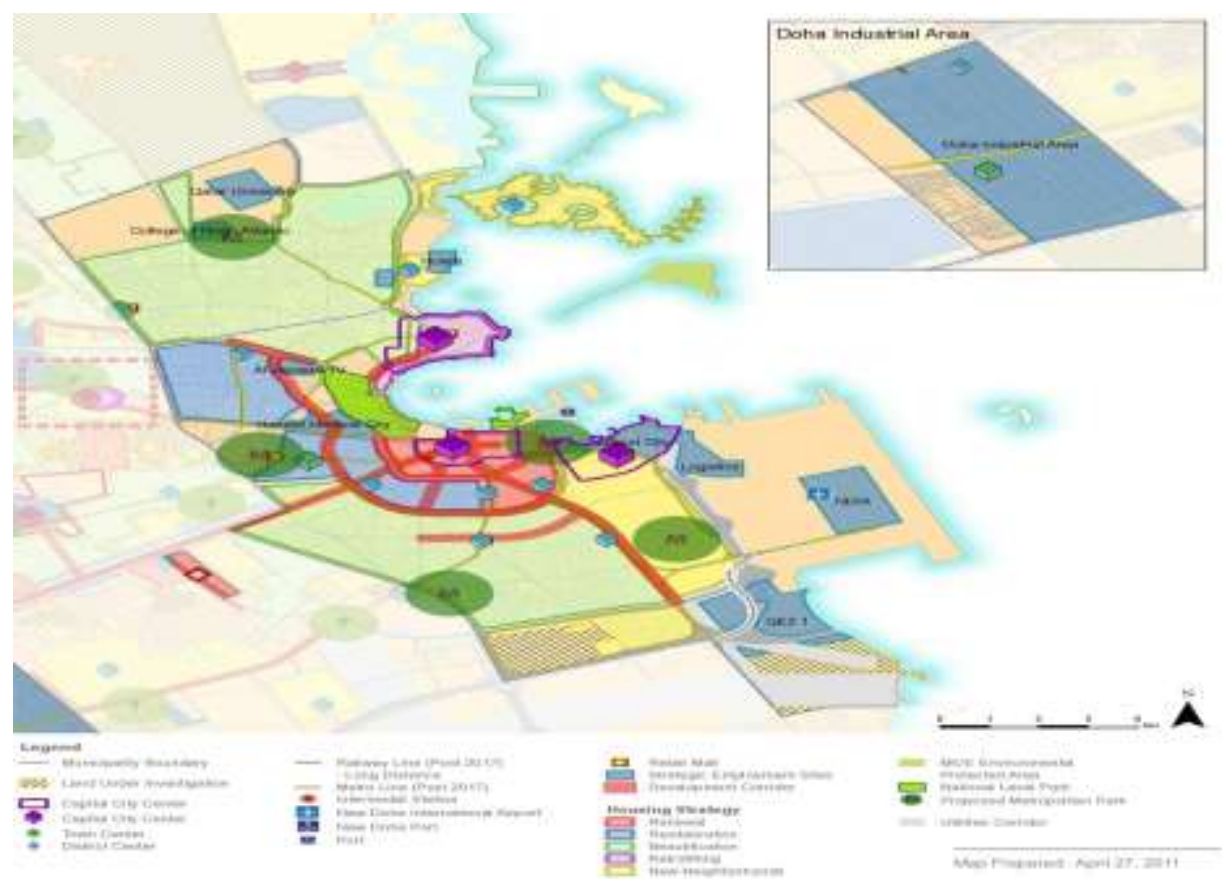

Fig.(8): The Development Strategy for Doha Municipality after 2011. 
Doha Municipality Planning Objectives: The planning objectives that apply to Doha Municipality are:

\section{Economic Prosperity}

- Promote the continued growth and diversification of the economy, by expanding new employment development in the Capital City Centers of West Bay, Downtown Doha and the future Airport City and the Town Centers of Al Sadd, Al Gharrafa and Old Al Matar

- Progressively redevelop the Doha Industrial Area as a light and medium impact industry area by addressing many of the physical, environmental and infrastructure constraints which currently exist.

- Develop a mixed use town center as part of the mixed use eco-friendly industrial park in the Doha Industrial Area.

- Promote an advanced manufacturing sector by developing QEZ1 as a hightech business park for light industry, manufacturing, logistics and associated commercial.

- Develop and enhance a series of internationally and nationally significant local cultural and arts facilities with appropriate spaces (both indoor and outdoor) for performances and festivals.

- Promote economic activity through main street programs designed at activating streets, returning the community to the centers and promoting communication and business knowledge transfer through social interaction within a high quality urban environment. 


\section{Living in the Community:}

- Promote Qatari living within the centers and within regeneration neighborhoods as an expansion of the traditional housing choice currently provided.

- Where Qatari housing is located and provided outside of centers, promote a strong Qatari community identity, through the built and natural environments as well as through the provision of services.

- Ensure housing options meet the needs of the changing expatriate population as part of sustainable land use change, promoting urban revitalization of neighborhoods in inner Doha.

- Maximize the flexibility and adaptability of existing and future housing stock to cater for the changing expatriate population to allow conversion and adaptation.

- Ensure the early provision and ready accessibility to necessary community services and facilities to support the daily living needs of residents

\section{Natural Environment:}

- Enhance the biodiversity of the municipality through the design of new green spaces and through creating open space corridors between destinations, particularly those that enhance the natural environment.

- Promote the provision of green space corridors and connections between the desert and sea.

- Enhance the natural environment, air quality and livability of the municipality by removing noxious and polluting industries from mixed-use and residential areas. 
- Promote energy and transport efficient urban developments to reduce the impact on the environment.

\section{Built Environment:}

- Create a series of connected mixed use Capital City, Town, District and Local Centers that meet the needs of their respective communities, and achieve the principles of Transit Oriented Development.

- Develop a world class waterfront Capital City area made up of the 3 Capital City Centers connected by the Corniche, the Grand Park and a world class public realm.

- Develop the Grand Park as the green heart of the City and a key community asset which also helps promote Doha as an internationally recognized destination.

- Develop Town Centers at Al Sadd, Al Gharrafa and Old Al Matar within Doha City and an Industrial Town Center at the Doha Industrial Area

- Develop District Centers at The Pearl, Fareej Kulaib, Rawdat Al Khail, Najma, Umm Ghuwallina, and Nuaija, through a combination of regeneration, redevelopment and green field development options.

- Identify existing local center opportunities for residential communities and along key corridors within the high density areas of Doha City.

- Identify corridors within Doha, as opportunities for transit boulevards that enhance and support the local community, through retail and residential opportunities.

- Revitalise and reconfigure the West Bay high density residential tower area as a high quality, pedestrian friendly and accessible neighborhood with a readily recognizable character and high level of living amenity. 
- Integrate the future Airport City and other mega and large scale urban projects with existing and other planned urban development.

- Improve the quality of neighborhoods in Inner Doha through regeneration that promotes family living and community interaction through the provision of improved high quality open spaces, public realm and community facilities.

- Protect the Al Asmakh and Al Najada neighborhoods (Zones 4 and 5) as an area of historical importance, reflecting the historic character of Downtown Doha.

- Develop buildings that are sustainable, address QSAS standards, and respond to the climate taking inspiration from historic Islamic architecture to create a new architectural language in Doha.

- Consider opportunities for creating new micro-climates in highly pedestrianized areas as a means to promote street activity.

- Provide a range of spaces from national significant parks through to pocket parks at the local level that meet the diverse needs of different cultures and age groups.

- Ensure open spaces promote and support key pedestrian routes.

\section{Movement:}

- Enhance opportunities for pedestrian and cycle movement through the municipality, providing a network of shaded routes that connect key facilities and transit stops to enhance thermal comfort of those on foot and cycle. 
- Promote Transit Oriented Development through the integration of land use and transport planning, in particular around Town and District Centers, especially where metro stations are located.

- Reduce the reliance on cars by providing alternative modes of public transport, including the development of a high quality mass transit system and promoting Salwa Road and Al Rayyan Road as Bus Rapid Transit corridors. .

- Design streets to provide safe, legible routes for pedestrians and cyclists.

- Design streets as public spaces, creating a strong relationship between buildings, roads and landscaping.

- Enhance the legibility of the city through the introduction of landscaping and public art along key corridors.

- Ensure that access to high quality public transport is available within easy walking distance to all residential communities.

- Maximize the role of the metro system and supporting public transport, and the existing road network in achieving sustainable transport outcomes.

- Ensure transport impacts are carefully considered and evaluated when new urban development proposals are being planned and approved.

\section{Utilities:}

- Enhance the utility network to ensure that the future demands of residents, workers and visitors to the municipality are met.

- Promote strategies for an efficient provision and distribution of utility network, which in turn leads to the overall reduction in the carbon footprint of the Country. 
- Ensure proposed urban development proposals fully factor in the impacts on existing utility networks, and their demand on new infrastructure as part of the planning and approval process.

Strategic Environmental Assessment (SEA): The Qatar Ministry Of Environment requires all major planning projects and master plans to undertake a 'Strategic Environmental Assessment (SEA). This is a systematic process for evaluating the environmental consequences of any proposed policy, plan or program initiatives in order to ensure they are fully included and appropriately addressed at the earliest appropriate stage of decision making on a par with economic and social considerations (Sadler, 1998). Such an assessment is necessary to ensure the sustainable outcome of any plan.

Strategic Environmental Assessment (SEA) is considered as one of the key instruments applied to integrate the environmental issues into a spatial planning process effectively (Alshuwaikhat 2005; Jones, et al., 2005). While Environmental Impact Assessment (EIA) has been used to assess the environmental impacts of development projects, The SEA is applied at a higher decision making level to assess the environmental impacts of policies, plans and programs (PPPs) (Sadler \& Verheem, 1996; Kjorven \& Lindhjem, 2002; Ahmed, Mercier and Verheem 2005).

Other widely acknowledged benefit of SEA process is that it can streamline and strengthen project EIA practices. Others argued that SEA can raise the environmental awareness and understanding amongst participants 
and can potentially enhance transparency and equity during the preparation of spatial plans (Jones, et al., 2005).

The SEA process is divided into four tasks (Table 3), where the assessment of SEA is depends on during the course of this study along with Figs. $5,6 \& 7$.

In Task 1 of the SEA process (Table 3), approximately 17 SEA objectives and 55 assessment criteria were developed. Meeting each criterion would ensure the environmental/ sustainable outcome, according to QNMP/ QNDP policy. If a policy or planned activity fails to meet the SEA objectives/criteria, it is necessary to undertake a detailed risk assessment. After evaluating the risk, the SEA process suggests a set of mitigating options.

In addition to the SEA evaluation required by the Ministry of Environment (MOE), the QNMP will deploy a robust sustainability assessment framework based on the six key "QNDF Sustainability Criteria" to critically examine its policies and establish benchmarks for achieving sustainable planning outcomes. It will establish specific targets and sustainability indicators where applicable. 
J. Environ. Sci.

Institute of Environmental Studies and Research - Ain Shams University

Table(3): Strategic Environmental Assessment (SEA)

\begin{tabular}{|c|c|c|}
\hline Task & Task Details \\
\hline \hline Task 1: Scoping & $\begin{array}{c}\text { Review Of relevant plans, policies and programs; } \\
\text { Setting the context and establishing the baseline; } \\
\text { Identifying key environmental, social and economic issues; } \\
\text { Developing the draft SEA framework; Stakeholder } \\
\text { engagement and } \\
\text { Set out the program for undertaking SEA in parallel with the } \\
\text { planning process, and identify those responsible for carrying } \\
\text { out the SEA process. }\end{array}$ \\
\hline $\begin{array}{c}\text { Contributing to the development of the policy, plan or } \\
\text { and Mitigation } \\
\text { program and appraising the relative effects of alternative } \\
\text { options; }\end{array}$ \\
$\begin{array}{c}\text { Predicting and evaluating the effects of the plan, policy or } \\
\text { program; } \\
\text { Identifying potential mitigation measures to improve the } \\
\text { environmental outcomes of the plan, policy or program; and } \\
\text { Suggesting appropriate systems and indicators to monitor the } \\
\text { effects of implementing the plan, policy or program. }\end{array}$ \\
\hline $\begin{array}{c}\text { Task 3: Reporting } \\
\text { and consultation }\end{array}$ & $\begin{array}{c}\text { Preparing a report on the assessment findings, mitigation } \\
\text { measures and monitoring proposals; and } \\
\text { Carrying out consultation on the SEA. }\end{array}$ \\
\hline $\begin{array}{c}\text { Task 4: monitoring } \\
\text { and evaluation }\end{array}$ & $\begin{array}{c}\text { Monitoring the effects of implementing the plan, policy or } \\
\text { program; and } \\
\text { Evaluating the effectiveness of the SEA process. }\end{array}$ \\
\hline
\end{tabular}

Environmental Assessment (EA): The MSDPs under assessment objectives and actions have been assessed using an interaction matrix on the different environmental (physical and biological), and social components, including air, water, soil, biodiversity, fauna, flora, landscape, human population and wealth, climatic factors, cultural heritage, and material goods (Table 4).

Each action is given (+ve) when the impact is potentially positive; (Nil) Nil when impact is irrelevant; or $(-\mathrm{ve})$ when if negative impact is likely to occur. If an action will potentially result in positive impacts, an 
environmental objective is set. On the contrary, if an action will potentially impact any environmental or social component, a mitigation measure is proposed. For every action, however, a monitoring measure is proposed include a Governance Indicator in line with the internationally recognized (UNESCO Governance Indicators). It is worth mentioning that separate environmental impact assessment (EIA) of programs and projects proposed in the coastal zone within Doha should be carried out.

Table (4): Doha MSDP Environmental Assessment

\begin{tabular}{|c|c|c|c|c|c|c|c|c|c|c|c|}
\hline Objectives & $\begin{array}{c}\text { Air } \\
\text { quality }\end{array}$ & $\begin{array}{l}\text { Water } \\
\text { quality }\end{array}$ & $\begin{array}{c}\text { Soil } \\
\text { quality }\end{array}$ & Geology & Fauna & Flora & $\begin{array}{c}\text { Habitats/ } \\
\text { Ecosystem }\end{array}$ & $\begin{array}{c}\text { PA's/ } \\
\text { Biodiversity }\end{array}$ & $\begin{array}{c}\text { Land } \\
\text { use }\end{array}$ & Population & $\begin{array}{l}\text { Public } \\
\text { Health }\end{array}$ \\
\hline \multicolumn{12}{|c|}{ I. Economic Prosperity } \\
\hline A. & -ve & -ve & -ve & Nil & Nil & Nil & -ve & Nil & tve & tve & tve \\
\hline B. & tve & tve & tve & Nil & Nil & Nil & -ve & Nil & tve & tve & tve \\
\hline $\mathrm{C}$ & tve & tve & tve & Nil & Nil & Nil & tve & Nil & tve & tve & tve \\
\hline D. & -ve & -ve & -ve & -ve & Nil & Nil & -ve & Nil & tve & tve & -ve \\
\hline E. & Nil & Nil & Nil & Nil & Nil & Nil & Nil & Nil & tve & tve & tve \\
\hline F. & Nil & Nil & Nil & Nil & Nil & Nil & Nil & Nil & tve & tve & tve \\
\hline \multicolumn{12}{|c|}{ II. Living in the community } \\
\hline A. & -ve & -ve & -ve & Nil & Nil & Nil & Nil & Nil & tve & tve & Nil \\
\hline B. & Nil & Nil & Nil & Nil & Nil & Nil & Nil & Nil & tve & tve & +ve \\
\hline C. & Nil & Nil & Nil & Nil & Nil & Nil & Nil & Nil & tve & tve & tve \\
\hline D. & Nil & Nil & Nil & Nil & Nil & Nil & Nil & Nil & tve & tve & tve \\
\hline E. & -ve & -ve & -ve & Nil & Nil & Nil & -ve & Nil & tve & tve & tve \\
\hline \multicolumn{12}{|c|}{ III. Natural environment } \\
\hline A. & tve & tve & tve & Nil & Nil & Nil & tve & Nil & tve & tve & tve \\
\hline B. & tve & tve & tve & Nil & Nil & Nil & tve & Nil & tve & tve & tve \\
\hline C. & tve & tve & tve & Nil & Nil & Nil & tve & Nil & tve & tve & tve \\
\hline D. & tve & tve & tve & Nil & Nil & Nil & tve & Nil & tve & tve & tve \\
\hline
\end{tabular}


J. Environ. Sci.

Institute of Environmental Studies and Research - Ain Shams University

Cont.Table (4): Doha MSDP Environmental Assessment

\begin{tabular}{|c|c|c|c|c|c|c|c|c|c|c|c|}
\hline Objectives & $\begin{array}{c}\text { Air } \\
\text { quality }\end{array}$ & $\begin{array}{l}\text { Water } \\
\text { quality }\end{array}$ & $\begin{array}{c}\begin{array}{c}\text { Soil } \\
\text { quality }\end{array} \\
\end{array}$ & Geology & Fauna & Flora & \begin{tabular}{|c|} 
Habitats/ \\
Ecosystem
\end{tabular} & $\begin{array}{c}\text { PA's/ } \\
\text { Biodiversity }\end{array}$ & $\begin{array}{c}\text { Land } \\
\text { use } \\
\end{array}$ & Population & $\begin{array}{l}\text { Public } \\
\text { Health }\end{array}$ \\
\hline \multicolumn{12}{|c|}{ IV. Built Environment } \\
\hline A. & -ve & -ve & -ve & Nil & Nil & Nil & -ve & Nil & tve & tve & tve \\
\hline B. & -ve & -ve & -ve & Nil & Nil & Nil & -ve & Nil & tve & tve & tve \\
\hline C. & tve & $-\mathrm{ve}$ & - ve & Nil & Nil & Nil & -ve & Nil & tve & tve & tve \\
\hline D. & -ve & -ve & -ve & Nil & Nil & Nil & -ve & Nil & tve & tve & -ve \\
\hline E. & -ve & -ve & -ve & Nil & Nil & Nil & -ve & Nil & tve & tve & tve \\
\hline F. & Nil & Nil & Nil & Nil & Nil & Nil & Nil & Nil & Nil & Nil & Nil \\
\hline G. & Nil & Nil & Nil & Nil & Nil & Nil & Nil & Nil & Nil & Nil & Nil \\
\hline H. & +ve & -ve & -ve & Nil & Nil & Nil & Nil & Nil & tve & tve & +ve \\
\hline I. & -ve & -ve & -ve & Nil & Nil & Nil & -ve & -ve & tve & tve & +ve \\
\hline J. & tve & tve & tve & Nil & Nil & Nil & tve & tve & tve & tve & tve \\
\hline $\mathrm{K}$. & Nil & Nil & Nil & Nil & Nil & Nil & Nil & Nil & tve & tve & Nil \\
\hline L. & tve & Nil & Nil & Nil & Nil & Nil & Nil & Nil & tve & +ve & tve \\
\hline M. & tve & Nil & Nil & Nil & Nil & Nil & Nil & Nil & tve & tve & tve \\
\hline Nil. & tve & Nil & Nil & Nil & Nil & Nil & Nil & Nil & tve & tve & tve \\
\hline 0. & tve & Nil & Nil & Nil & Nil & Nil & Nil & Nil & tve & tve & +ve \\
\hline \multicolumn{12}{|c|}{ V. Movement } \\
\hline A. & tve & Nil & Nil & Nil & Nil & Nil & Nil & Nil & tve & tve & tve \\
\hline B. & tve & Nil & Nil & Nil & Nil & Nil & Nil & Nil & tve & tve & tve \\
\hline C. & tve & Nil & Nil & Nil & Nil & Nil & Nil & Nil & tve & tve & tve \\
\hline D. & tve & Nil & Nil & Nil & tve & Nil & Nil & Nil & tve & tve & tve \\
\hline E. & tve & Nil & Nil & Nil & tve & Nil & Nil & Nil & tve & tve & tve \\
\hline F. & tve & Nil & Nil & Nil & tve & Nil & Nil & Nil & tve & tve & tve \\
\hline G. & tve & Nil & Nil & Nil & tve & Nil & Nil & Nil & tve & tve & $+\mathrm{ve}$ \\
\hline H. & tve & Nil & Nil & Nil & tve & Nil & Nil & Nil & tve & tve & $+\mathrm{ve}$ \\
\hline I. & tve & Nil & Nil & Nil & tve & Nil & Nil & Nil & tve & tve & tve \\
\hline \multicolumn{12}{|c|}{ VI. Utilities } \\
\hline A. & Nil & Nil & Nil & Nil & tve & Nil & Nil & Nil & tve & tve & tve \\
\hline B & -ve & -ve & -ve & Nil & tve & Nil & Nil & Nil & tve & tve & tve \\
\hline C. & Nil & Nil & Nil & Nil & Nil & Nil & Nil & Nil & tve & tve & + tve \\
\hline
\end{tabular}

(+ve): positive impact; (-ve): negative impact and (Nil): irrelevant impact 


\section{RESULTS AND DISCUSSION}

The impacts of MSDP in this research are classified into three categories as shown in table 4:

- (+ve): positive impact

- (-ve): negative impact

- (Nil): irrelevant impact

\section{Positively impact}

- Doha MSDP intends to promote the continued growth and diversification of the economy by expanding new development in the Capital City Centers.

- Doha MSDP aims to promote an advanced manufacturing hub by developing Qatar Economic Zone 1. It might also useful to include educational activities within the park, a school of industrial engineering may be an added value.

- Doha MSDP would ensure the early provision and ready accessibility to necessary community services and facilities to support the daily living needs of residents. The social impacts would be positive; however construction of such community services should be dealt with carefully to avoid environmental impacts.

- Doha MSDP seeks to enhance the air quality of the municipality through the design of new green spaces and through creating open space corridors between destinations, particularly those that enhance the natural environment as positive impacts through selection of the floral species for creating green and open spaces from local plant species to avoid invasive species and reduce water demand for irrigation. 
- The provision of green space corridors and connections between the desert and sea should be considered carefully. Though it would have positive environmental and social impacts, the selection of the floral species that would be used for creating green and open spaces should rely on local plant species. This would reduce water consumption for irrigation, and avoid invasive species, especially in desert areas.

- Doha MSDP aims to promote energy and transport efficient urban development to reduce the impact on the environment. This would have positive impacts, but there might not be enough regulations for energy (Merier, et al., 2013). It is recommended to have regulations for energy and transport efficiency, particularly in Doha, where most of the population lives.

\section{Negatively impact}

- Downtown Doha and the future Airport City and the Town Centers of Al Sadd, Al Gharrafa and Old Al Matar. The West bay is located directly on the Arabian Gulf Coast. The area is a world class business center where most of governmental authorities and mega companies having their premises. The area is; however, subject to sea level rise in the 2100 horizon. Waterfront areas are prone and subject to flooding. Therefore, the results of climate change and sea level rise of the ICZM project should be considered during the revisit of the MSDP of Doha to exclude areas vulnerable to sea level rise. Otherwise coastal protection should be considered as adaptation measures to climate change impacts. 
- Zone 1 includes a high-tech business park for light industry, manufacturing, logistics and associated commercial activities. The (Qatar Economic Zone 1) QEZ1 is located directly on the coast, and construction is going on now. The impacts of this huge economic prosperity would require a project scale monitoring and management measures during both conduction and operation phases.

- The proposal to develop a world class waterfront Capital City area made up of the 3 Capital City Centers connected by the Corniche have a negative impact by harm the natural marine environment.

\section{Recommendations:}

- Future iterations of the National Spatial Strategy and/or National Development Plan must recognize the increasing vulnerability of coastal populations to coastal and climate change risks e.g. flooding and sea level rise and establish a strong institutional system for monitoring of coastal indicators, identifying and assessing in particular, the land subsidence in the coastal area.

- Strategic Environmental Assessment (SEA) for future development plans must carry out with strong follow up taking Sea Level Rise (SLR) into consideration and building up a strong early warning system and contingency plans against flooding.

- It is recommended that connectivity of urban centers in Doha should rely on sustainable corridors, and encourage the use of international ideas that respect the national context. As an example, is the use of local materials and plant species. 
- The idea of creating opportunities for new micro-climates in highly pedestrianized areas as a means to promote street activity is needed in Doha, which has higher temperatures and humid weather. To reduce an implication for public health and energy, it is recommended to select the new micro-climate instruments that are sustainable and do not result in public health issues or increase energy consumption.

\section{REFERENCES}

Ahmed, K.; Mercier, J.R. and Verheem, R. (2005): 'Strategic Environmental Assessment-Concept and Practice', Environment Strategy Notes, World Bank, June 2005, pp. 1-6.

Alshuwaikhat, H.M. (2005): 'Sustainable Planning: The need for Strategic Environmental Assessment-based municipal planning in Saudi Arabia', Journal of Environmental Assessment Policy and Management, 7(3): 387-405.

Arab Forum for Environment and Development (AFED), (2009): Arab environment: climate change, impact of climate change on Arab countries. http://www.afedonline.org/afedreport09/

Ayhan M. E. and Alothman, A. (2009): Sea level rise within the west of Arabian Gulf using tide gauge and continuous GPS measurements. Geophysical Research Abstracts. volume 11, EGU 2009-6006-1.

Church J. A. and N.J. White (2011): Sea-level rise from the late 19th to the early 21st century. Survey in Geophysics, 32(5) 585-602.

Cooper, J.A.G. and McKenna, J., (2009): Boom and bust: the influence of macroscale economics on the world's coasts. J. Coast. Res. 253, 533-538.

Domurat, G.W. and Wakeman, T.H., (1991): The California Coastal Zone Experience. New York, Am. Soc. Civ. Eng., p. 278-297. 
Duxbury, J. and Dickinson, S., (2007): Principles for sustainable governance of the coastal zone: in the context of coastal disasters. Ecol. Econ. 63, 319-330.

Goodstadt, V. \& Partidário, M.R. (2010): Spatial Planning and Environmental Assessments. A Quick Guide to the Economics of Ecosystems and Biodiversity for Local and Regional Policy Makers. TEEB, 23-105.

Integrated Coastal Zone Management Plan for the State of Qatar, Climate Change and Sea Levl Rise Study (ICZM-CCSLR, 2014). Ministry of Municipality and Urban Planning (MMUP).

Intergovernmental panel on climate change in the fifth assessment report (IPCC), (2013): http://www.ipcc.ch/report/ar5/wg1/.

Intergovernmental panel on climate change in the fifth assessment report (IPCC), (2007): Summary for Policymakers. Working Group II, IPCC, Brussels.

Jones, C.; Baker, M.; Carter, J.; Jay, S.; Short, M. and Wood C. (2005): Strategic Environmental Assessment and land-use Planning: An International Evaluation, Earthscan, London.

Kjörven, O. and Lindhjem, H. (2002): 'Strategic Environmental Assessment in World Bank Operations; Experience to Date - Future Potential', The International Bank for Reconstruction and Development/ THE WORLD BANK, Washington, D.C.

Martínez, M.L., Intralawan, A., Vázquez, G., Pérez-Maqueo, O., Sutton, P., Landgrave,R., (2007): The coasts of our world: ecological, economic and social importance. Ecol. Econ. 63, 254-272.

Meier, A., Sabeeh, S. and Darwish, M. (2013): Complexities of saving energy in Qatar, in European council for energy efficient economy, summer study. Belambra les criques, Toulon, France.

Nerem, R.S., Chambers, D., Choe C. and Mitchum G.T. (2010): Estimating Mean Sea Level change from the TOPEX and Jason Altimeter Mission. Marine Geodesy. 33(1 supp1): 435. 
Nicholls, R.J., Hoozemans, F.M.J. and Marchand, M., (1999): Increasing flood risk and wetland losses due to global sea-level rise: regional and global analyses. Glob. Environ. Change 9 (Suppl. 1), S69S87,

Romanowicz, R. and Beven, K.J. (2003): Estimation of flood inundation probabilities as conditioned on event inundation maps. Water Resources Research, 39(3): http://dx.doi.org/1029/2001WR001056.

Sadler, B. and Verheem, R. (1996): "Strategic Environmental assessment: Status, Challenges and Future Directions", Ministry of Housing, Spatial Planning and the Environment, The Hague, The Netherlands.

Sadler, B. (1998): 'Strategic Environmental Assessment: Institutional Arrangements, Practical Experience and Future Directions. Institute of Environmental Assessment International Workshop on Strategic Environmental Assessment, Organized by the Japan Environment Agency, Tokyo, 26-27 November 1998.

Therivel, R. \& Partidário, M.R. (1996): "The Practice of Strategic Environmental Assessment", Earthsacn, London.

Zhang, W.H. and Cundy, T.W. (1989): Modelling of two-dimensional overland-flow. Water Resources Research 25(9): 2019-2035. 


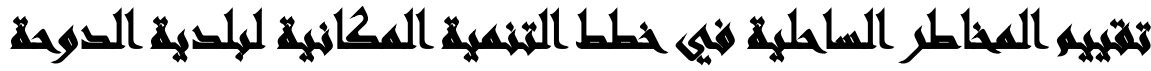

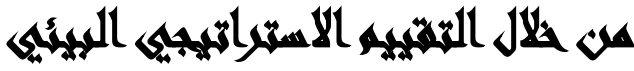

\section{[1]}

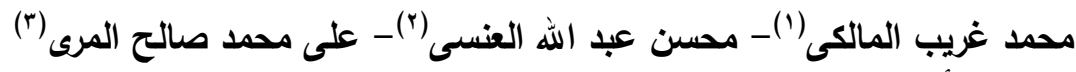

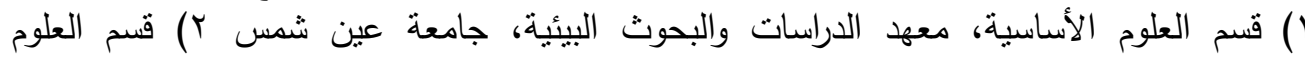
البيولوجية والبيئية، كلية الآداب والعلوم، جامعة قطر r ب) قسم المختبرات، هيئة الاشغال العالة العامة،

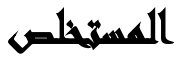

تم تصميم التقييم البيئي الاستراتيجي لمساعدة البلدان على جعل سياساتها وخططها وبرامجها

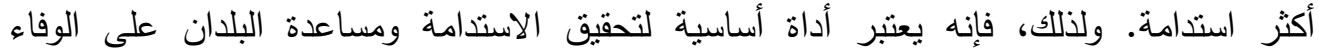

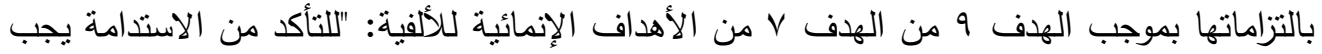

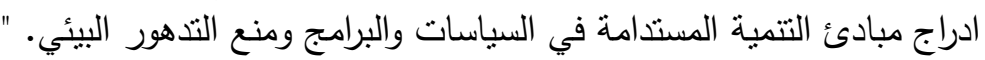

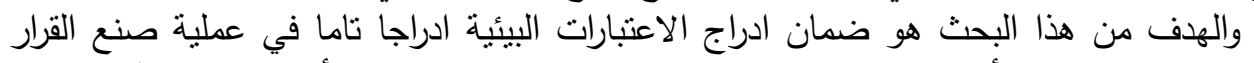

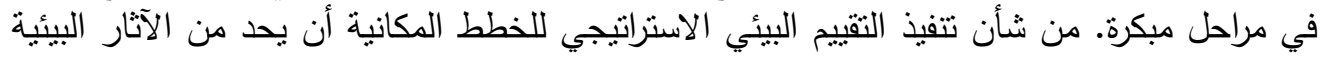

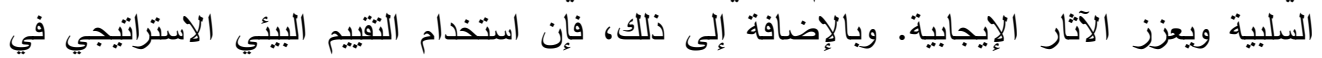

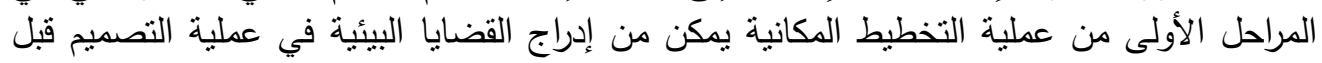

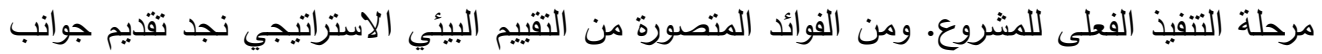
الاستدامة من طبيعته الاستباقية والاستراتيجية وقدرته على إدماج الجوانب الإنب البيئية بفعالية مع القضايا

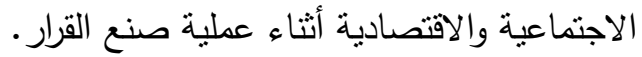

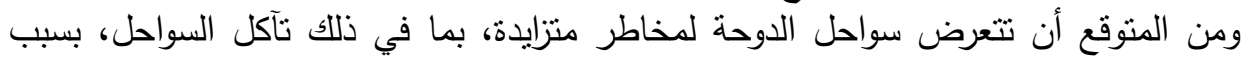

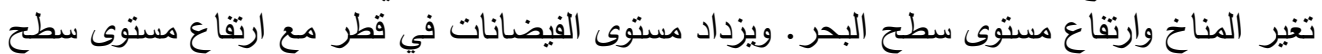

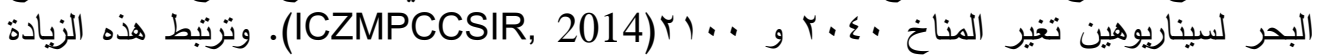

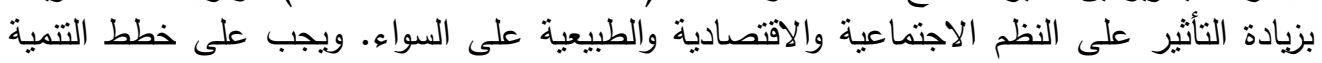

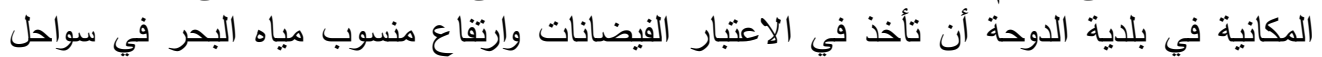

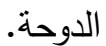

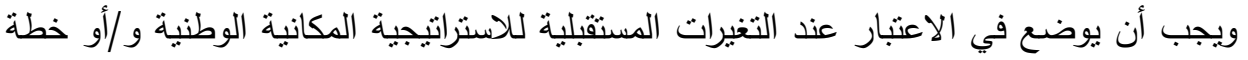

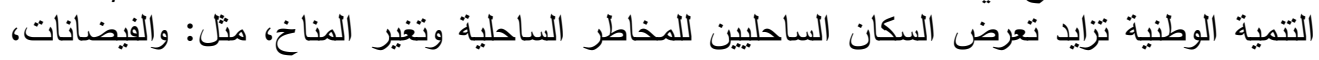

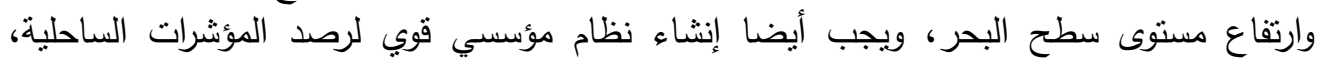

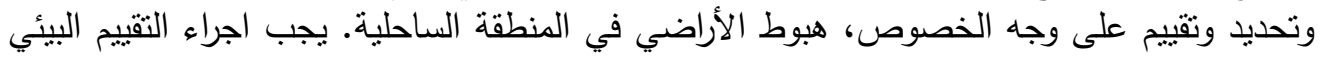

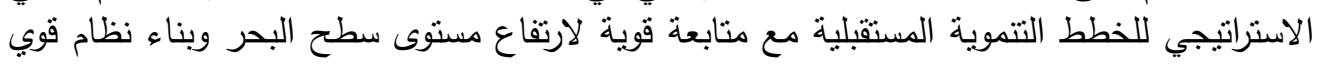
للإنذار المبكر وخطط الطوارئ ضد الفيضانات. 